\title{
Survival in small cell lung cancer in India: Prognostic utility of clinical features, laboratory parameters and response to treatment
}

\author{
Mohan A, Goyal A, Singh P, Singh S, Pathak AK*, Bhutani $\mathbf{M}^{\star}$, Pandey RM${ }^{\star \star}$, Guleria R \\ Departments of Medicine, *Medical Oncology and **Biostatistics, All India Institute of Medical Sciences, \\ Ansari Nagar, New Delhi, India
}

Correspondence to: Prof. Randeep Guleria, E-mail: randeepguleria2002@yahoo.com

\begin{abstract}
BACKGROUND: Predictors of survival and response to treatment in patients with small cell lung cancer (SCLC) are ill-defined and unclear. In an attempt to assess the impact of common presenting symptoms and laboratory values on survival, we undertook this retrospective review of patients with SCLC. To our knowledge, there is no study on survival in SCLC patients from the Indian subcontinent. DESIGN: Retrospective Cohort study. MATERIALS AND METHODS: All newly diagnosed small cell lung cancer cases from December 2001 through December 2004, were identified and clinical data on presenting symptoms and laboratory findings from their hospital records, noted. The influence of various pretreatment factors on survival was investigated using Kaplan-Meier plots and Cox multivariate regression model. RESULTS: 76 subjects were included ( $84 \%$ males, $91 \%$ smokers). $57 \%$ patients had five or more symptoms at presentation. Cumulative symptom burden was strongly associated with survival $(P=0.02)$. Survival was also significantly related with Karnofsky performance status (KPS) $(P=0.04)$, disease extent $(P=0.03)$ and symptomatic response to treatment $(P<0.001)$. Patients with higher hemoglobin $(P=0.02)$, serum sodium $(P=0.04)$ and serum globulin $(P=0.02)$, survived significantly longer. By multivariate regression analysis, hemoglobin, KPS and brain metastases, were significant predictors of survival ( $P=0.01, P=0.02, P<0.01$ respectively). CONCLUSION: Cumulative symptom burden, KPS, disease extent and symptomatic assessment of improvement after treatment, are useful predictors of survival. This has important clinical implications, keeping in view, the infrastructure and cost involved in more objective tests like CT scan, for evaluation of disease extent and prognosis. These findings can provide a simple basis for predicting prognosis in small cell lung cancer, especially in developing countries like ours.
\end{abstract}

Key words: Small cell lung cancer, survival, prognostic factors, performance status, symptom burden, symptomatic response to treatment.

Small cell lung cancer (SCLC) accounts for 14-18\% of malignant lung tumors and differs from other types by its early and widespread dissemination. ${ }^{[1,2]}$ The aggressive nature of this variant is evidenced by the fact that the overall 2 -year survival rate is $5.9 \%$ and the 5 year survival rate, a dismal $2.4 \% .^{[3,4]}$ These figures have not changed significantly over the past few decades, in spite of several advances in chemotherapy and radiotherapy ${ }^{[5]}$ The early identification of simple prognostic factors in such a tumor is important, as it would assist in defining sub-groups for which different treatment modalities could be targeted, for example, a sub-group of patients having no reasonable chance of long term survival could be considered for short-term 
chemotherapy associated with minimal toxicity or offered palliative care only, whereas patients with better chance of long term survival could be treated more aggressively with curative treatment.

Even though SCLC is chemosensitive, a significant proportion of patients are unable to tolerate chemotherapy. This is due to the fact that most patients present with extensive disease and a poor performance status, associated with severe debilitating symptoms related to the primary tumor, as well as its metastatic manifestations. In this setting, it is important to identify factors that can predict increased likelihood of survival in these patients. These factors would be useful in selecting patients, most likely to attain survival benefit. This has important implications in a developing country like India, where economic constraints and limited health-care resources with a huge patient burden, do not allow universal accessibility to high-quality medical facilities.

Certain other prognostic factors such as disease extent and performance status are well known, while others may still be unrecognized. ${ }^{[6-13]}$ The prognostic utility of these factors have mainly been evaluated in developed nations. Equivalent data from developing countries is lacking. To our knowledge, there is no study on survival in SCLC patients from the Indian subcontinent.

Patients with lung cancer often suffer from multiple symptoms, both respiratory and non-respiratory. However, very few studies have evaluated the influence of cumulative symptom burden at the time of diagnosis, on the overall survival of these patients. Most of the studies were conducted more than a decade ago and subsequent studies have focused more on assessing the utility of latest imaging modalities. Similarly, response to treatment is assessed mainly by using computerized tomography (CT) scan and other imaging modalities. However, the usefulness of the patient's assessment of symptomatic benefit, has not received much attention.

This study was thus carried out with the following objectives (a) to evaluate the impact of pre-treatment clinical and laboratory parameters on the prognosis of patients with SCLC, (b) to assess the relationship between cumulative symptom burden and outcome and (c) to evaluate whether a symptomatic and/or radiological response to treatment actually translates into survival benefit.

\section{Materials and Methods}

In this retrospective cohort study, medical records of 76 patients with a pathologically confirmed diagnosis of
SCLC, registered at the medical oncology department of All India Institute of Medical Sciences, New Delhi, India, between December 2001 and December 2004, were studied. Apart from the details regarding the patient's age, gender, contact information, smoking status and pack-years, the dates of first visit and diagnosis were also recorded. In case of patients diagnosed outside the hospital, the pathology slides were reviewed and the date of diagnosis at this hospital was taken for analysis.

Karnofsky performance status (KPS $)^{[14]}$ and the following symptoms were recorded-shortness of breath, cough, chest pain, hemoptysis, significant weight loss (>10\% of premorbid body weight in 6 months), anorexia, hoarseness of voice, fever, neurological symptoms (focal weakness, seizures), superior vena cava (SVC) obstruction (defined as puffiness of face, facial swelling or flushing of face) and other symptoms that the patient complained of at presentation. Cumulative symptom burden was defined as the numerical sum of affirmative symptoms at initial presentation.

Relevant investigations were done to evaluate local extent and metastases. These included CT scans (chest, abdomen and brain), bone marrow examination and bone scan. Limited disease was defined as tumor confined to one hemithorax, but including mediastinum, ipsilateral supraclavicular lymph nodes and ipsilateral pleural effusions. Diseases beyond this stage was classified as extensive. ${ }^{[15]}$

The baseline laboratory parameters recorded were- total serum protein, serum albumin, serum globulin, serum alkaline phosphatase (SAP), calcium, phosphorus, bilirubin, transaminases (AST/ALT), urea, creatinine, sodium, potassium, hemoglobin, total leukocyte count (TLC) and platelet count. Serum lactate dehydrogenase (LDH) was made a part of the pretreatment work up only in January 2004.

Details of the treatment received i.e., chemotherapy (CT)/radiotherapy (RT)/ both and the type of treatment (CT-etoposide + cisplatin/ irinotecan + cisplatin and RT-curative/ palliative), were noted. The number of cycles and the dates of initiation and completion of treatment were also recorded. Standard criteria were used to assess radiological response to treatment as complete response (CR), partial response (PR), progressive disease (PD) and no response (NR). ${ }^{[16]}$ Symptomatic response was assessed after completion of chemotherapy and was categorized into no, mild, moderate and significant, based on the patient's subjective assessment of improvement over his baseline symptoms $(0-25 \%, 25-50 \%, 50-75 \%$ and $>75 \%$ 
improvement, respectively).

All the patients were contacted by mail/telephone. The survival data was obtained either from the patients themselves, or their relatives. For those dead, the date of death was recorded and was used to calculate survival. For the patients where survival information was not obtained, the interval between the date of diagnosis and the date of last follow up was used to calculate survival duration. ${ }^{[17]}$

\section{Statistical methods}

Median value was used to categorize clinical and laboratory parameters into 'high' or 'low values'. This was done to eliminate the possibility that cut-off points were selectively chosen to maximize the difference between groups, with respect to survival. Such a practice invalidates the usual interpretation attached to a $P$-value. ${ }^{[18]}$

Univariate analysis was performed using Kaplan-Meier $\operatorname{method}^{[19]}$ for survival and log-rank test ${ }^{[20]}$ for comparisons. Variables examined as dichotomous were: Age ( $<55$ years vs. $\geq 55$ years), gender (male vs. female), smoking (non-smoker vs. smoker), stage (limited vs. extensive), KPS ( $\geq 70$ vs. $<70$ ), symptom burden ( $\leq 5$ vs. $>5$ ), SVC obstruction (no vs. yes), brain metastases (no vs. yes), bone metastases (no vs. yes), liver metastases (no vs. yes), adrenal metastases (no vs. yes) and all the lab parameters (<median vs. $\geq$ median). The parameters with a significant impact were entered in a stepwise forward Cox multivariate analysis, ${ }^{[21]}$ to find the hazard ratios with $95 \%$ confidence intervals. STATA 8.0 statistical software was used for data analysis. $P$-value smaller than 0.05 was considered statistically significant

\section{Results}

The clinical characteristics of all patients were evaluated as a group and are summarized in Table $1.77 .6 \%$ of the patients were below 65 years of age. Shortness of breath was the commonest symptom observed, followed by cough, anorexia and chest pain. Most patients were current/ex-smokers and presented with extensive disease. The median survival was 10.1 months. On objective assessment of response to CT, 3 patients $(6.5 \%)$ had CR, 33 (71.7\%) had PR, 6 (13\%) had PD and 4 (8.8\%) had NR.

Disease extent, KPS, symptom burden and metastases to brain and adrenals at the time of diagnosis, were found to be significantly associated with survival [Table 2] [Figures 1 and 2]. Of the 17 laboratory parameters studied, statistical significance was obtained for
Table 1: Patient characteristics $(n=76)$

\begin{tabular}{|c|c|}
\hline Variable & Total (\%) \\
\hline Age (years) ${ }^{*}$ & $54.9( \pm 9.2)$ \\
\hline \multicolumn{2}{|l|}{ Gender } \\
\hline Males & 84.2 \\
\hline Females & 15.8 \\
\hline Current/ex-smokers ${ }^{\dagger}$ & 90.8 \\
\hline Pack years ${ }^{\ddagger}$ & $25(2.5-125)$ \\
\hline \multicolumn{2}{|l|}{ Disease Stage } \\
\hline Limited & 27.6 \\
\hline Extensive & 72.4 \\
\hline KPS & $70(30-80)$ \\
\hline Symptom burden ${ }^{\ddagger}$ & $5(3-8)$ \\
\hline$\leq 5$ & 57.9 \\
\hline$>5$ & 42.1 \\
\hline Duration of symptoms (months) ${ }^{\ddagger}$ & $3(1-12)$ \\
\hline \multicolumn{2}{|l|}{ Symptoms } \\
\hline Shortness of breath & 80.3 \\
\hline Cough & 76.3 \\
\hline Chest pain & 64.5 \\
\hline Hemoptysis & 23.7 \\
\hline Anorexia & 75.0 \\
\hline Weight loss & 67.1 \\
\hline Fever & 39.5 \\
\hline Hoarseness of voice & 36.8 \\
\hline SVC obstruction & 32.9 \\
\hline Others ${ }^{\S}$ & 13.1 \\
\hline \multicolumn{2}{|l|}{ Metastases\| } \\
\hline Liver & 40.0 \\
\hline Bone & 18.2 \\
\hline Brain & 10.9 \\
\hline Adrenals & 7.3 \\
\hline Others" & 9.1 \\
\hline \multicolumn{2}{|l|}{ Number of metastatic sites** } \\
\hline Single & 61.0 \\
\hline Multiple & 39.0 \\
\hline \multicolumn{2}{|l|}{ Treatment received } \\
\hline Both CT and RT & 56.6 \\
\hline Either $\mathrm{CT}$ or $\mathrm{RT}$ & 32.9 \\
\hline None & 10.5 \\
\hline
\end{tabular}

*Mean value ( \pm Standard deviation)

tPatients who were current/ex-smokers $(n=69)$

‡Median value (Range)

§Includes dysphagia, neurological symptoms like seizures and focal deficits.

III patients with extensive disease $(n=55)$

"Includes metastases to opposite lung, abdominal wall

${ }^{* *}$ Among those who had metastases $(n=41)$ 
Table 2: Median duration of survival: Impact of clinical features

\begin{tabular}{|c|c|c|c|c|}
\hline Variable & Median su & (in days) & $P$-value $\left(\mathrm{LRT}^{\star}\right)$ & Unadjusted HR $(95 \% \mathrm{CI})$ \\
\hline Age: $<55 \mathrm{yrs}^{\dagger}$ vs. $\geq 55$ yrs & 304 & 298 & 0.9320 & $1.03(0.5-2.0)$ \\
\hline Gender: male $^{\dagger}$ vs. female & 298 & 538 & 0.2294 & $0.5(0.2-1.5)$ \\
\hline Smoking: non-smoker ${ }^{\dagger}$ vs. smoker & 538 & 304 & 0.6363 & $1.4(0.3-5.9)$ \\
\hline Stage: limited $^{\dagger}$ vs. extensive & 459 & 296 & 0.0295 & $3.0(1.1-8.5)$ \\
\hline KPS: $\geq 70^{\dagger}$ vs. $<70$ & 324 & 121 & 0.0478 & $1.5(1.0-2.1)$ \\
\hline Symptom burden: $\leq 5^{\dagger}$ vs. $>5$ & 324 & 242 & 0.0248 & $2.1(1.1-4.1)$ \\
\hline SVC obstruction: no $^{\dagger}$ vs. yes & 321 & 242 & 0.2928 & $1.4(0.7-2.8)$ \\
\hline Brain metastases: no $^{\dagger}$ vs. yes & 324 & 77 & 0.0001 & $5.3(2.1-13.5)$ \\
\hline Bone metastases: no ${ }^{\dagger}$ vs. yes & 324 & 182 & 0.3317 & $1.5(0.6-3.7)$ \\
\hline Liver metastases: no ${ }^{\dagger}$ vs. yes & 429 & 298 & 0.1966 & $1.6(0.8-3.2)$ \\
\hline Adrenal metastases: no $^{\dagger}$ vs. yes & 304 & 83 & 0.0354 & $3.0(1.0-8.5)$ \\
\hline
\end{tabular}

${ }^{\dagger}$ Referent category

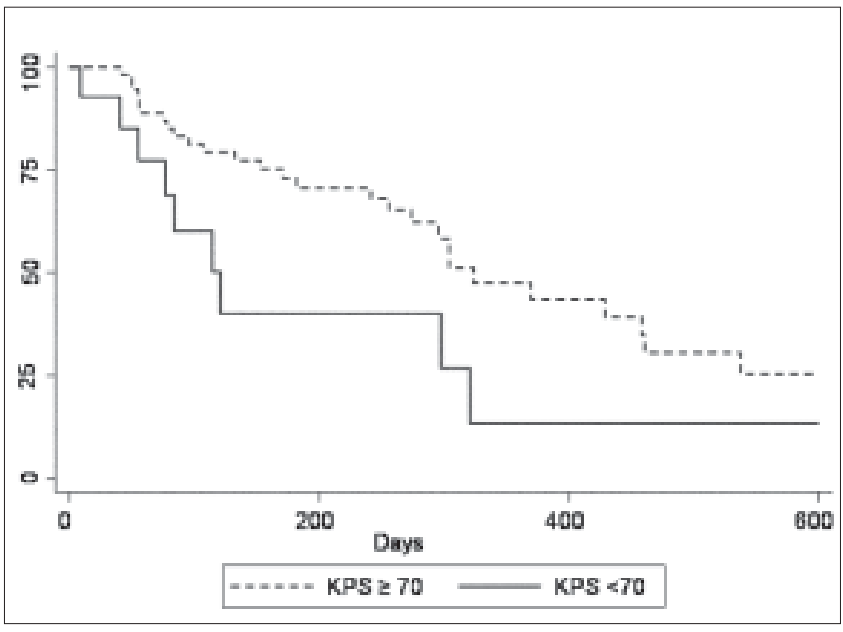

Figure 1: Survival related to KPS. $(P=0.048)$

hemoglobin, serum sodium and serum globulin [Table 3]. Patients who received multimodal (combined CT and RT) treatment had longer survival, as compared to those who received no treatment $(P<0.001)$, or single modality (either CT or RT) treatment $(P<0.001)$ [Figure 3]. Patients who had a moderate to significant symptomatic response to treatment had a better prognosis, than those who showed a mild or no response $(P<0.001)$ [Figure 4]. However, survival in patients with $\mathrm{CR}$ or $\mathrm{PR}$ as compared to those with NR or $\mathrm{PD}$, was not statistically significant $(P=0.968)$.

Multiple logistic regression analysis was used to determine relationships of the potential variables related to survival. The candidate variables selected had statistically significant $(P<0.05)$ relation with survival status. These variables were symptom burden, disease

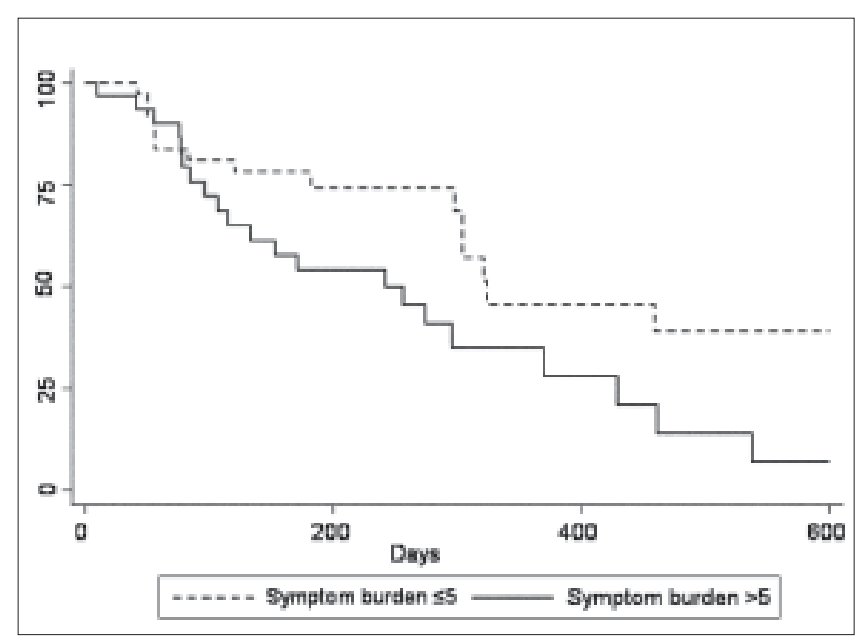

Figure 2: Survival related to symptom burden $(P=0.025)$

extent, KPS, hemoglobin, serum globulin, serum sodium, modality of treatment received and symptomatic response to treatment. The hazard ratios and $95 \%$ confidence intervals are shown in Table 4 . Patients with a symptom burden of $>5$ had a relative risk of mortality 5.3 times as compared to those with symptom burden $\leq 5$. Extensive disease was associated with about 7 times greater likelihood of mortality, when compared with limited disease. Patients with a poor performance status (KPS <70) had double the relative risk of death in comparison to patients with KPS $\geq 70$. Inclusion of brain and adrenal metastases in the multiple regression analyses, highlighted the poor prognostic significance of brain metastases, low hemoglobin $(<12.8 \mathrm{~g} / \mathrm{dL})$ and poor performance status (KPS $<70)$.

Age, sex, smoking status, pack-years, KPS and 
Table 3: Median duration of survival: Influence of pretreatment laboratory parameters

\begin{tabular}{|c|c|c|c|c|c|c|c|}
\hline \multirow[t]{2}{*}{ Variable } & \multirow[t]{2}{*}{$\mathrm{n}$} & \multirow{2}{*}{$\begin{array}{l}\text { Median value } \\
\text { (Range) }\end{array}$} & \multicolumn{2}{|c|}{ Median survival (in days) } & \multirow[t]{2}{*}{ Referent } & \multirow{2}{*}{$\begin{array}{c}\text { Risk } \\
\text { category }\end{array}$} & \multirow{2}{*}{$\begin{array}{l}\text { Unadjusted } \\
\text { HR }(95 \% \mathrm{Cl})\end{array}$} \\
\hline & & & Low value* & High value $^{\dagger}$ & & & \\
\hline Hemoglobin $(\mathrm{g} / \mathrm{dL})^{\ddagger}$ & 74 & $12.8(8.5-18.2)$ & 274 & 459 & $\geq 12.8$ & $<12.8$ & $2.2(1.1-4.5)$ \\
\hline $\operatorname{TLC}\left(/ \mathrm{mm}^{3}\right)$ & 74 & $9500(3800-24500)$ & 298 & 321 & $\geq 9500$ & $<9500$ & $0.8(0.4-1.6)$ \\
\hline Platelet Count $\left(\times 10^{3} / \mathrm{mm}^{3}\right)$ & 72 & $234(59-681)$ & 298 & 370 & $\geq 234$ & $<234$ & $1.4(0.7-2.8)$ \\
\hline Sodium $(\mathrm{mEq} / \mathrm{L})^{\ddagger}$ & 70 & $138(116-154)$ & 256 & 429 & $\geq 138$ & $<138$ & $2.1(1.0-4.2)$ \\
\hline Potassium (mEq/L) & 70 & $4.4(2.5-5.7)$ & 324 & 321 & $\geq 4.4$ & $<4.4$ & $0.9(0.5-1.9)$ \\
\hline Calcium (mg/dL) & 69 & $9.5(7.2-11.5)$ & 304 & 321 & $<9.5$ & $\geq 9.5$ & $1.2(0.6-2.4)$ \\
\hline Phosphorus (mg/dL) & 69 & $3.7(2.0-5.1)$ & 370 & 321 & $<3.7$ & $\geq 3.7$ & $0.7(0.3-1.4)$ \\
\hline Urea (mg/dL) & 70 & $25(13-62)$ & 304 & 429 & $<25$ & $\geq 25$ & $0.6(0.3-1.2)$ \\
\hline Creatinine (mg/dL) & 70 & $0.9(0.5-4.4)$ & 256 & 321 & $<0.9$ & $\geq 0.9$ & $1.0(0.4-2.5)$ \\
\hline Total serum protein $(\mathrm{g} / \mathrm{dL})$ & 65 & $7.5(6.1-8.8)$ & 298 & 321 & $\geq 7.5$ & $<7.5$ & $1.3(0.6-2.9)$ \\
\hline Serum albumin $(g / d L)$ & 65 & $3.8(2.5-4.6)$ & 370 & 256 & $\geq 3.8$ & $<3.8$ & $0.6(0.3-1.2)$ \\
\hline Serum globulin $(\mathrm{g} / \mathrm{dL})^{\ddagger}$ & 65 & $3.7(2.7-4.6)$ & 274 & 538 & $\geq 3.7$ & $\geq 3.7$ & $2.5(1.1-5.4)$ \\
\hline Serum bilirubin (mg/dL) & 69 & $0.6(0.4-0.9)$ & 321 & 274 & $<0.6$ & $\geq 0.6$ & $1.5(0.7-3.2)$ \\
\hline AST (U/L) & 70 & $35(13-411)$ & 324 & 321 & $<35$ & $\geq 35$ & $0.8(0.4-1.6)$ \\
\hline ALT (U/L) & 70 & $33(9-443)$ & 324 & 321 & $<33$ & $\geq 33$ & $0.9(0.4-1.8)$ \\
\hline Alkaline phosphatase (U/L) & 68 & $146(82-1484)$ & 256 & 324 & $<146$ & $\geq 146$ & $0.3(0.1-1.6)$ \\
\hline LDH (U/L) & 23 & $298(125-618)$ & 304 & 538 & $<298$ & $\geq 298$ & $0.8(0.4-1.6)$ \\
\hline
\end{tabular}

*Low value is $<$ the median value for the respective variable.

tHigh value is $\geq$ the median value for the respective variable

${ }^{\ddagger} P<0.05$ (median survival duration significantly higher, using log rank test)

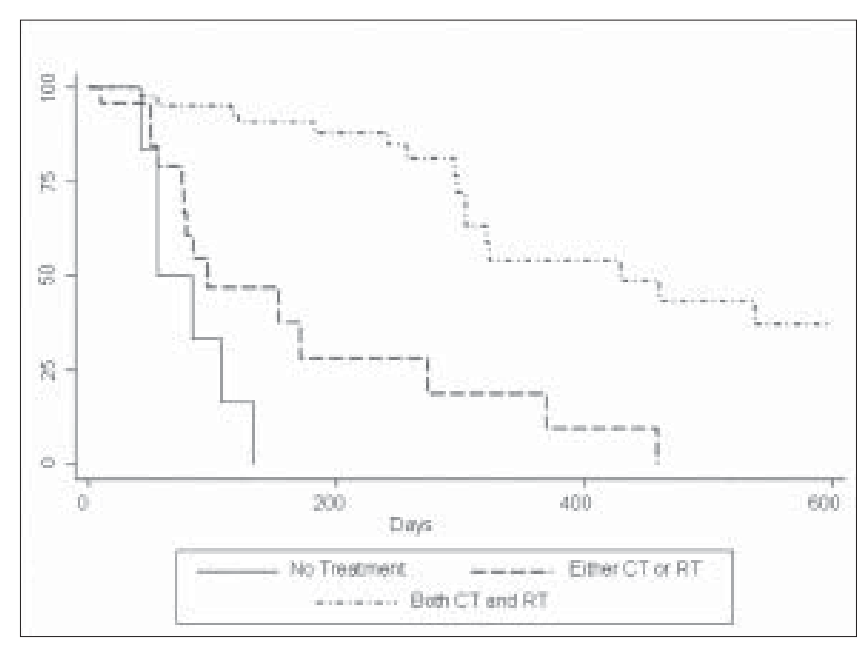

Figure 3: Survival related to modality of treatment received.

symptom duration were not related to the disease extent. Among the various symptoms analyzed, only weight loss was significantly associated with extensive disease $(P<0.001)$.

High SAP and low hemoglobin were associated with

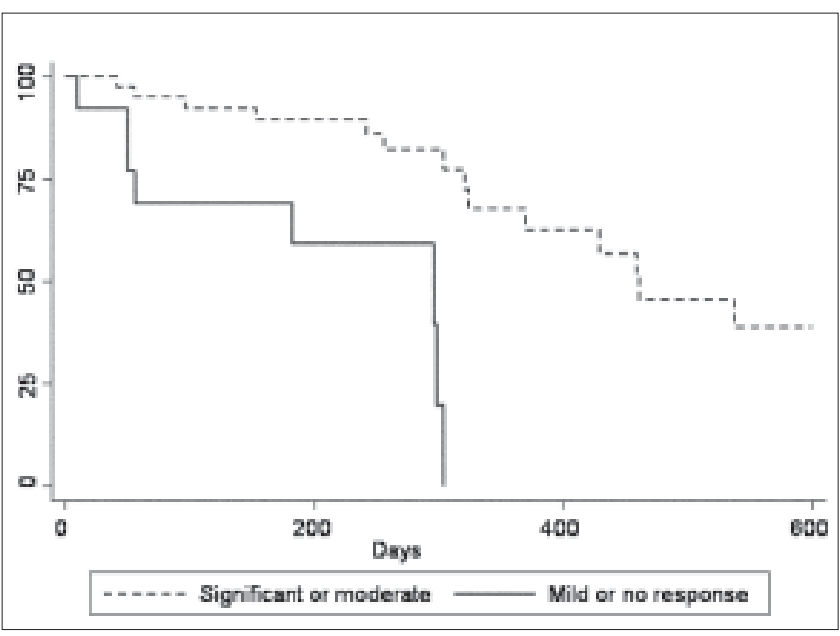

Figure 4: Survival related to symptomatic response to treatment. $(P<0.001)$

metastasis to liver $(P=0.027)$ and bone marrow $(P=0.004)$, respectively. All patients received chemotherapy consisting of Cisplatinum and Etoposide, every three weeks for four cycles. Subsequent radiotherapy was given in the dose of 45-50 Gy (with conventional fractionation), for 4-6 monthly cycles. In 
Table 4: Multivariate analysis of prognostic factors in SCLC. Hazard ratios and $95 \% \mathrm{Cl}$

\begin{tabular}{|c|c|c|c|c|}
\hline Variable & & Adjusted hazard ratio & $95 \% \mathrm{Cl}$ & $P$-value \\
\hline \multicolumn{5}{|c|}{ Without inclusion of brain metastases as a significant variable } \\
\hline \multirow[t]{2}{*}{ Symptom burden } & $\leq 5$ & 1.0 (reference) & & \\
\hline & $>5$ & 5.3 & $1.5-17.8$ & 0.008 \\
\hline \multirow[t]{2}{*}{ Disease extent } & Limited & 1.0 (reference) & & \\
\hline & Extensive & 7.3 & $0.9-58.4$ & 0.061 \\
\hline \multirow[t]{2}{*}{ KPS } & $\geq 70$ & 1.0 (reference) & & \\
\hline & $<70$ & 2.0 & $1.0-4.0$ & 0.038 \\
\hline \multicolumn{5}{|c|}{ With inclusion of brain metastases as a significant variable } \\
\hline \multirow[t]{2}{*}{ Hemoglobin $(g / d L)$} & $>12.8$ & 1.0 (reference) & & \\
\hline & $\leq 12.8$ & 5.8 & $1.6-21.2$ & 0.008 \\
\hline \multirow[t]{2}{*}{ Brain metastases } & No & 1.0 (reference) & & \\
\hline & Yes & 29.8 & $3.6-245.1$ & 0.002 \\
\hline \multirow[t]{2}{*}{ KPS } & $\geq 70$ & 1.0 (reference) & & \\
\hline & $<70$ & 2.3 & $1.2-4.5$ & 0.015 \\
\hline
\end{tabular}

addition, palliative radiotherapy was given for extensive local disease or symptomatic metastatic sites, as per requirement. The most common toxic effects of CT included nausea/vomiting (40.6\%), diarrhea/constipation $(34.4 \%)$ and myelosuppression (28.1\%). Febrile neutropenia and neurotoxicity each were observed in $4.7 \%$ of patients.

\section{Discussion}

The patients in the present study were on an average 5 years younger as compared to patients in most other studies and was comparable to other Indian studies. ${ }^{[2,22]}$ A much higher proportion of patients were below 65 years of age. ${ }^{[22]}$ However, age did not correlate significantly with survival in our patients. The prognostic value of age has been advocated by some, but not other studies. ${ }^{[3,7,8,23,24]}$ In spite of the overall lower mean age, the proportion of patients presenting with extensive disease was higher than that reported in previous trials. ${ }^{[17,25]}$ This could be attributed to (a) patient delay with a long interval between onset of the first symptom and seeking medical care due to ignorance about the disease, presence of other background symptoms, poor socio-economic status and lack of access to qualified health care professionals and specialized facilities (especially in far-flung geographical locales), (b) delay in diagnosis with a long interval between first presentation and confirmation of diagnosis due to high prevalence of other diseases, notably tuberculosis, which presents with similar symptoms (hence considerably diluting the clinical suspicion of malignancy) and (c) delay in treatment initiation (possibly due to high patient burden, limited centers offering oncology care and patient's inability to afford chemotherapy), allowing a considerably time for stage migration due to exponential growth of tumors. Western literature estimates that the median delay time in non-small cell lung cancer from onset of symptoms to initiation of treatment, is 4.6 months ( 3.4 months for advanced stage IV), whereas the median in-hospital delay (time of first hospital visit to start of treatment), is 1.6 month. ${ }^{[26]}$ However, in this study, this delay did not affect survival. Patients with more advanced disease had shorter delay time, probably reflecting the fact that these patients got medical attention quicker than others. In another study of patients with resectable lung cancer, patients had to wait for a median period of 109 days after presentation, in the hospital to the time of operation. ${ }^{[27]}$ No study has specifically addressed the issue of time delay in diagnosis after the patient presents to a medical center. Although corresponding data from India is lacking, it can safely be assumed that the delays in diagnosis and treatment would not be less than these figures.

The median duration of survival of patients with limited and extensive disease was 15.3 months and 9.8 months, respectively, which was comparable to previous studies. ${ }^{[25]}$ As observed in previous studies, females 
survived longer than males, although this difference was not statistically important. ${ }^{[3,28]}$ The prognostic significance of pre-treatment KPS is well known. ${ }^{[3,23,24,29]}$ It is a useful surrogate marker, not just for predicting survival, but also to assess quality of life and response to therapy. Likewise, the prognostic value of disease extent has been well documented in several studies. ${ }^{[7,18,24,30,31]}$

Brain and adrenal metastases were present in $11 \%$ and $7 \%$ of the patients with extensive disease, respectively and significantly related to survival. ${ }^{[32-36]}$ Importance of number of metastatic sites has also been reported, ${ }^{[19,29,37]}$ however, it was found to be insignificant in our study.

LDH was not found to be a prognostic marker, unlike other studies. ${ }^{[23,24,29]}$ This was probably because of low number of patients in which serum $\mathrm{LDH}$ estimation was done $(n=23)$.

The significant relationship between survival and hemoglobin concentration ${ }^{[18]}$ and serum sodium, corroborates previous observations. ${ }^{[13,18]}$ Serum globulin was related to survival in our study, although other authors did not find this relation. ${ }^{[13]}$ Low serum globulins may indicate an immune-deficient state that may predispose these patients to various life-threatening infections, thereby reducing survival duration. Serum albumin has been considered an important predictor of survival in several studies; ${ }^{[10,11,18,29]}$ however such an association was not observed by Cerny et al, ${ }^{[13]}$ nor in the present study. SAP also was not associated with survival in the present study, whereas it has been found by other studies to be related to survival. ${ }^{[11,13]}$

We found a significant correlation between symptom burden and survival, although individual symptoms per se were not significant prognostic indicators. Coy et al (1981) studied 1839 unresected lung cancer patients and reported that fewer number of symptoms at the time of diagnosis and a longer time interval between the first symptom and diagnosis, were associated with better survival. ${ }^{[38]}$ Patients with lung cancer often suffer from multiple symptoms which could be features of local disease (shortness of breath, chest pain, cough, hemoptysis), locally advanced disease (hoarseness of voice, facial swelling, dysphagia), extrathoracic spread (seizures, focal neurological deficits, bone pain) and weight loss and anorexia (which are imagined to be possible signs of sub-clinical systemic disease) $;^{[39,40]}$ this was also observed in this study, as weight loss was strongly associated with extensive disease.

The importance of symptom assessment is re- emphasized, based on the results of this study. A high cumulative symptom burden would be suggestive of poor outcome. Consequently, such an assessment of symptom burden may serve as a simple yet important prognostic factor, independent of the stage of the disease. In resource-poor developing countries like ours, this could be used as a simple, inexpensive parameter, for dividing patients into groups that is more likely to derive therapeutic benefit.

The degree of symptomatic response to treatment was strongly related to patient outcome. This was in contrast to the correlation of radiological response to treatment with survival. It has to be noted that radiological response to treatment was assessed only in 46 patients. This implies that many patients may not undergo repeat radiological evaluation for judging the response to treatment. The reasons for this are primarily financial, in our setting. Anticipation of poor prognosis may be another factor. It is also noteworthy that even 'objective' measurements (by CT Scan) of tumor size are prone to observer errors, so response rates to CT that are derived from such measurements are best considered approximations. ${ }^{[41]}$ In such situations, a patient-dependent evaluation of symptomatic response to treatment can serve as an important tool in predicting survival.

We were however limited in our study in abstracting symptom information from existing hospital records and we could not collect data from the patients themselves. Medical records vary in the completeness of data and some hidden bias may have entered the study in this way. Symptomatic response of the patient to treatment was done subjectively; objective criteria were not used while recording this aspect. Also, since radiological response to treatment was assessed in only $60 \%$ patients, interpretations based on this should be made with caution.

\section{Conclusion}

In conclusion, it is clear that the role of symptoms in assessing prognosis should not be ignored, in spite of the advent of newer imaging modalities and complex staging procedures. In addition, the degree of symptomatic improvement following treatment may be of greater relevance in predicting outcome, than radiological improvement, thus relieving the financial burden involved in repeated objective tests like CT scan. Greater emphasis on these simple clinical parameters may prove extremely cost effective in developing countries and will help in prioritizing patient care according to expected survival benefit. 


\section{References}

1. Simon GR, Wagner H. American College of Chest Physicians. Small Cell Lung Cancer. Chest 2003;123:259S-71S.

2. Prasad R, James P, Kesarwani V, Gupta R, Pant MC, Chaturvedi $A$, et al. Clinicopathological study of bronchogenic carcinoma. Respirology 2004;9:557-60.

3. Souhami RL, Law K. Longevity in small cell lung cancer. A report to the Lung Cancer Subcommittee of the United Kingdom Coordinating Committee for Cancer Research. Br J Cancer 1990;61:584-9.

4. Davis S, Wright PW, Schulman SF, Scholes D, Thorning D, Hammar S. Long term survival in small cell carcinoma of the lung: A population experience. J Clin Oncol 1985;3:80-91

5. Lassen U, Osterlind K, Hansen M, Dombernowsky P, Bergman B, Hansen $\mathrm{HH}$. Long-term survival in small cell lung cancer: Posttreatment characteristics in patients surviving 5 to 18 years: An analysis of 1,714 consecutive patients. J Clin Oncol 1995;13:1215-20

6. Dearing MP, Steinberg SM, Phelps R, Anderson MJ, Mulshine JL, Ihde DC, et al. Outcome of patients with small cell lung cancer: Effect of changes in staging procedures and imaging technology on prognostic factors over 14 years. J Clin Oncol 1990;8:1042-9.

7. Osterlind K, Ihde DC, Ettinger DS, Gralla RJ, Karrer K, Krauss S, et al. Staging and prognostic factors in small cell carcinoma of the lung. Cancer Treat Rep 1983;67:3-9.

8. Aisner J, Whitley NO. Staging of small cell lung cancer: Do we need a new staging system? In: Hansen $\mathrm{HH}$, Kristjansen $\mathrm{P}$, editors. Management of Small cell Lung Cancer. Elsevier: Amsterdam; 1989. p. $45-54$

9. George SL. Identification and assessment of prognostic factors. Semin Oncol 1988;15:462-71.

10. Vincent MD, Ashley SE, Smith IE. Prognostic factors in small cell lung cancer: A simple prognostic index is better than conventional staging. Eur J Cancer Clin Oncol 1987;23:1589-99.

11. Souhami RL, Bradbury I, Geddes DM, Spiro SG, Harper PG, Tobias JS. Prognostic significance of laboratory parameters measured at diagnosis in small cell carcinoma of the lung. Cancer Res 1985;45:2878-82.

12. Souhami RL, Earl HM, Ash CM, Spiro SG, Geddes D, Harper PG, et al. Prognostic factors in patients with small cell lung cancer: Preliminary results from a large randomized study. Antibiot Chemother 1988;41:77-82.

13. Cerny T, Blair V, Anderson H, Bramwell V, Thatcher N. Pretreatment prognostic factors and scoring system in 407 small cell lung cancer patients. Int J Cancer 1987;39:146-9.

14. Karnofsky DA, Abelmann WH, Craver LF, Burchenal JH. The use of nitrogen mustard in the palliative treatment of cancer. Cancer 1948; 1:634-56.

15. Hansen HH, Dombernowsky P, Hirsch FR. Staging procedures and prognostic features in small cell anaplastic bronchogenic carcinoma. Semin Oncol 1978;5:280-7.

16. Miller AB, Hoogstraten B, Staquet M, Winkler A. Reporting results of cancer treatment. Cancer 1981;47:207-14.

17. Maestu I, Pastor M, Gomez-Codina J, Aparicio J, Oltra A, Herranz $\mathrm{C}$, et al. Pretreatment prognostic factors for survival in small cell lung cancer: A new prognostic index and validation of three new prognostic indices on 341 patients. Ann Oncol 1997;8:547-53.

18. Cohen MH, Makuch R, Johnston-Early A, Ihde DC, Bunn PA Jr, Fossieck BE Jr, et al. Laboratory parameters as an alternative to performance status in prognostic stratification of patients with small cell lung cancer. Cancer Treat Rep 1981;65:187-95.

19. Feliu J, Gonzalez Baron M, Artal A, Ordonez A, Cebreiros I, Martin $\mathrm{G}$, et al. Bone marrow examination in small cell lung cancer-When is it indicated? Acta Oncol 1991;30:587-91.

20. Kaplan EL, Meier P. Non-parametric estimation from incomplete observations. J Am Stat Assoc 1958;53:457-81.
21. Peto R, Pike MC, Armitage P, Breslow NE, Cox DR, Howard SV, et al. Design and analysis of randomized clinical trials requiring prolonged observations in each patient II. Analysis and examples. Br J Cancer 1977;35:1-39.

22. Rawson NS, Peto J. An overview of prognostic factors in small cell lung cancer. A report from the Subcommittee for the Management of Lung Cancer of the United Kingdom Coordinating Committee for Cancer Research. Br J Cancer 1990;61:597-604.

23. Osterlind $\mathrm{K}$, Hansen $\mathrm{HH}$, Hansen M, Dombernowsky P, Andersen PK. Long term disease free survival in small cell carcinoma of the lung: A study of clinical determinants. J Clin Oncol 1986;4:1307-13.

24. Arrigada R, de The H, Le Chevalier T, Thomas F, Ruffie P, de Cremoux $\mathrm{H}$, et al. Limited small cell lung cancer: Possible prognostic impact of initial chemotherapy doses. Bull Cancer 1989;76:605-15.

25. Fizazi K, Cojean I, Pignon JP, Rixe O, Gatineau M, Hadef S, et al. Normal Serum Neuron Specific Enolase (NSE) Value after the First Cycle of Chemotherapy. Cancer 1998;82:1049-55.

26. Myrdal G, Lambe M, Hillerdal G, Lamberg K, Agustsson T, Stahle E. Effect of delays on prognosis in patients with non-small cell lung cancer. Thorax 2004;59:45-9.

27. Billing JS, Wells FC. Delays in the diagnosis and surgical treatment of lung cancer. Thorax 1996;51:903-6.

28. Shepherd FA, Evans WK, Feld R, Young V, Patterson GA, Ginsberg $\mathrm{R}$, et al. Adjuvant chemotherapy following surgical resection for small cell carcinoma of the lung. J Clin Oncol 1988;6:832-8.

29. Wolf M, Holle R, Hans K, Drings P, Havemann K. Analysis of prognostic factors in 766 patients with small cell lung cancer: The role of sex as a predictor of survival. Br J Cancer 1991;63:986-92.

30. Bergman B, Sullivan M, Sorenson S. Quality of life during chemotherapy for small cell lung cancer. Acta Oncol 1991;30:947-57.

31. Suga J, Saijo N, Shinkai T, Eguchi K, Sasaki Y, Tamura T, et al. Long term survival in patients with small cell lung cancer. Jpn J Clin Oncol 1986;16:309-15.

32. De Wet M, Falkson G, Rapoport BL. Small cell lung cancer: Analysis of factors influencing the response to treatment and survival. Oncology 1994;51:523-34.

33. Penel N, Brichet A, Prevost B, Duhamel A, Assaker R, Dubois F, et al. Prognostic factors of synchronous brain metastasis from lung cancer. Lung Cancer 2001;33:143-54.

34. Ihde DC, Makuch RW, Carney DN, Bunn PA, Cohen MH, Matthews MJ, et al. Prognostic implications of stage of disease and sites of metastases in patients with small cell carcinoma of the lung treated with intensive combination chemotherapy. Am Rev Respir Dis 1981;123:500-7.

35. Crane JM, Nelson MJ, Ihde DC, Makuch RW, Glatstein E, Zabell A, et al. A comparison of computed tomography and radionuclide scanning for detection of brain metastases in small cell lung cancer. J Clin Oncol 1984;2:1017-24.

36. Maurer LH, Tulloh M, Weiss RB, Blom J, Leone L, Glidewell O, et al. A randomized combined modality trial in small cell carcinoma of the lung: Comparison of combination chemotherapy-radiation therapy versus cyclophosphamide-radiation therapy effects of maintenance chemotherapy and prophylactic whole brain irradiation. Cancer 1980;45:30-9.

37. Sagman U, Maki E, Evans WK, Warr D, Shepherd FA, Sculier JP, et al. Small cell carcinoma of the lung: Derivation of a prognostic staging system. J Clin Oncol 1991;9:1639-49.

38. Coy P, Elwood JM, Coldman AJ. Clinical indicators of prognosis in unresected lung cancer. Chest 1981;80:453-8.

39. Johnston RN, Smith DH. Symptoms and survival in lung cancer. Lancet 1968;2:588-91.

40. Senior RM, Adamson JS. Survival in patients with lung cancer. An appraisal of Feinstein's symptom classification. Arch Intern Med 1970; 125:975-80.

41. Moertel CG, Hanley JA. The effect of measuring error on the results of therapeutic trials in advanced cancer. Cancer 1976;38:388-94. 